SARA TANDERUP

Ph.d. i Litteraturhistorie og post.doc.

Center for Litteratur mellem Medier, Aarhus Universitet

\title{
"BYENS BEDSTE BRUGTE BØGER" Bogen som vare og samlerobjekt i nye eksperimenterende romaner
}

\begin{abstract}
Som mindesmærke over min mest ophidsende auktionsoplevelse rager endnu i dag Balzacs Chagrinskindet op over lange rækker af franske bøger i mit bibliotek. Det var i 1915 på Rümann-auktionen hos Emil Hirsch [...]. Jeg var kommet til eftersynet hos Emil Hirsch, jeg havde haft 40 eller 50 bind mellem hænderne, men dette bind med det brændende ønske om aldrig at skulle give det fra mig igen. Auktionsdagen kom. [...] [Emil Hirsch] udråbte prisen, jeg bød noget over med hjertet i halsen og fuldstændig klar over, at jeg ikke kunne tage konkurrencen op med nogen af de tilstedeværende store samlere. Men auktionarius gik [...] videre med de sædvanlige formularer, "ingen højere" og tre slag - mig forekom de at være adskilt af en evighed - til hammerslag. (Benjamin 87-88).
\end{abstract}

Handel med bøger er en intens affære, i hvert fald som Walter Benjamin beskriver det i essayet "Jeg pakker mit bibliotek ud": med anspændt stemning om auktionsbordet, bud leveret med bankende hjerte og et brændede ønske om at eje en bestemt bog - ydermere en bestemt udgave af en bestemt bog. Bøger er i denne sammenhæng noget mere end bare tekster. De er handelsvarer, samlerobjekter, som værdsættes for deres materielle kvaliteter såvel som for deres litterære indhold. I essayet reflekterer Benjamin videre over samlerens forhold til bogen. For samleren "er besiddelsen det allerdybeste forhold, man overhovedet kan have til ting" (91). Derfor bliver købet af bogen til et drama i sig selv. 
272 KULTUR \& KLASSE * $124 * 2017$

HANDEL

Denne artikel skal ikke handle om bogsamleren, men om det blik på bogen, som Benjamin skitserer: et fokus på bogen som fysisk ting, der, for at blive i Benjamins vokabular, får en nærmest auratisk værdi: det enkelte eksemplar bliver værdsat for sine materielle kvaliteter og bliver genstand for hjertebanken og brændede begær, samtidig med at den også bare er en handelsvare med en pris som alle andre ting. Dette blik er ikke i sig selv noget nyt, som Benjamins essay vidner om. Alligevel vil jeg argumentere for, at det blik på bogen som værdifuld samlerobjekt og handelsvare, som Benjamin indfanger, i særlig grad præger vores såkaldt postdigitale nutid, hvor bogen ikke længere kan tages for givet.

I dag kan jeg finde Benjamins essay bare ved at google titlen. Jeg kan læse det på min computer, min iPad eller telefon. Teksten er ikke længere uløseligt knyttet til bogen - og derfor er vi de sidste 10-15 år blevet mere opmærksomme på bogen som medium og genstand. Hvor man i størstedelen af det 20. århundrede, ikke mindst inden for litteraturteorien, har været orienteret mod teksten som en immateriel størrelse, er man begyndt at interessere sig for værkets materielle indpakning. Det, som i Benjamins samtid var forbeholdt de få, samlerne eller boghistorikerne, nemlig blikket for det fysiske objekt, bliver i dag udbredt og udforsket både i akademiske og skønlitterære sammenhænge.

I denne nye situation får bogen en ny, modsætningsfyldt status. På den ene side kan man iagttage en nostalgisk tendens i såvel litteraturen som kulturen generelt til at dyrke bogen som garant for en traditionel litterær kultur, der positioneres i modsætning til, og endog antages at være hævet over, de kommercielle logikker, som angiveligt dominerer den nye mediekultur. Bogen er, ifølge denne diskurs, en art sidste bastion for litterær fordybelse og kunst for kunstens skyld. På den anden side tilføjer bogens forstærkede status som samlerobjekt den også kommerciel værdi som handelsvare i den moderne mediekultur.

I det følgende undersøger jeg, hvordan denne dobbelthed kommer til udtryk i to nyere værker, Mette Hegnhøjs Ella er mit navn vil du købe det? fra 2014 (herefter Ella) og J.J. Abrams og Doug Dorsts S. fra 2013. Begge er eksperimenterende romaner, som tematisk og formelt sætter fokus på bogen som samlerobjekt og handelsvare. Hegnhøjs børnelitterære værk foregår i et antikvariat og omhandler 12-årige Ella, der bor i antikvariatets baglokale. 
Værket iscenesætter Ellas forsøg på at bryde ud af antikvariatet og væk fra en traditionel bogkultur, idet det trækker på strategier fra avantgardens konkretpoesi og 6o'ernes kunstnerbøger. I $S$. fremstilles bogen som rum for modstand mod en verden styret af kapitalitiske tyranner og nye medier - samtidig med at værket selv er indlejret i mediekulturens kommercielle logikker, som understreget af de markedsføringsstrategier, der omgiver det. De to eksempler peger på forskellig vis på den trykte bogs aktuelle status som et gammelt medium, der positioneres i modsætning til den nye mediekultur, samtidig med at den er (og altid har været) en handelsvare og som sådan fungerer på den nye mediekulturs kommercielle præmisser.

\section{ELLA OG REMATERIALISERINGEN AF LITTERATUREN}

Mette Hegnhøjs Ella præsenteres i en æske af brunt pap, med aftryk af kaffepletter på låget og titlen påtrykt et imiteret klistermærke. Æsken er holdt sammen af en elastik, hvorpå der er skrevet med håndskrift: "Forsigtig! Indeholder poetsne". Inden i æsken er der 138 løse maskinsskrevne papirark, holdt sammen af et blomstret bånd, og mellem siderne finder man 'postsneen': en masse små runde stykker papir af den slags, der opstår, når man bruger en hullemaskine. Bag på æsken præsenteres værket med en note fra forlaget: "Dette er Ellas efterladte noter, som vi fandt dem i Privaten bag Antikvariatet i en æske under Ellas seng".

Noten er underskrevet med en håndskreven signatur fra forlaget og er med til at give indtryk af værket som en autentisk genstand, et objet trouvé, der står i direkte forbindelse til den historie, det fortæller. Selvom der ikke er tale om en egentlig bog i betydningen et trykt kodeks, spiller værket på klassiske forestillinger om bogkultur, ikke mindst idet historien om den 12-årige Ella foregår i et antikvariat. Med sin æsteticering af bogobjektet; sit blomstrede bånd og løse sider af tyk cremefarvet karton synes værket umiddelbart at forbinde sig til den tilgang til bøger, som Benjamin skitserer: bogen som eksklusivt auratisk samlerobjekt.

Dette indtryk står dog i kontrast til værkets skildring af bøgerne i antikvariatet. Bøgerne stammer fra dødsboer og beskrives af Ella som "døde folks bøger" (63), der "lugter af langsom død" (9). De fremstilles som støvede rester fra en død kultur. Ella læser dem ikke; de skal først og fremmest 
274 KULTUR \& KLASSE * $124 * 2017$

HANDEL

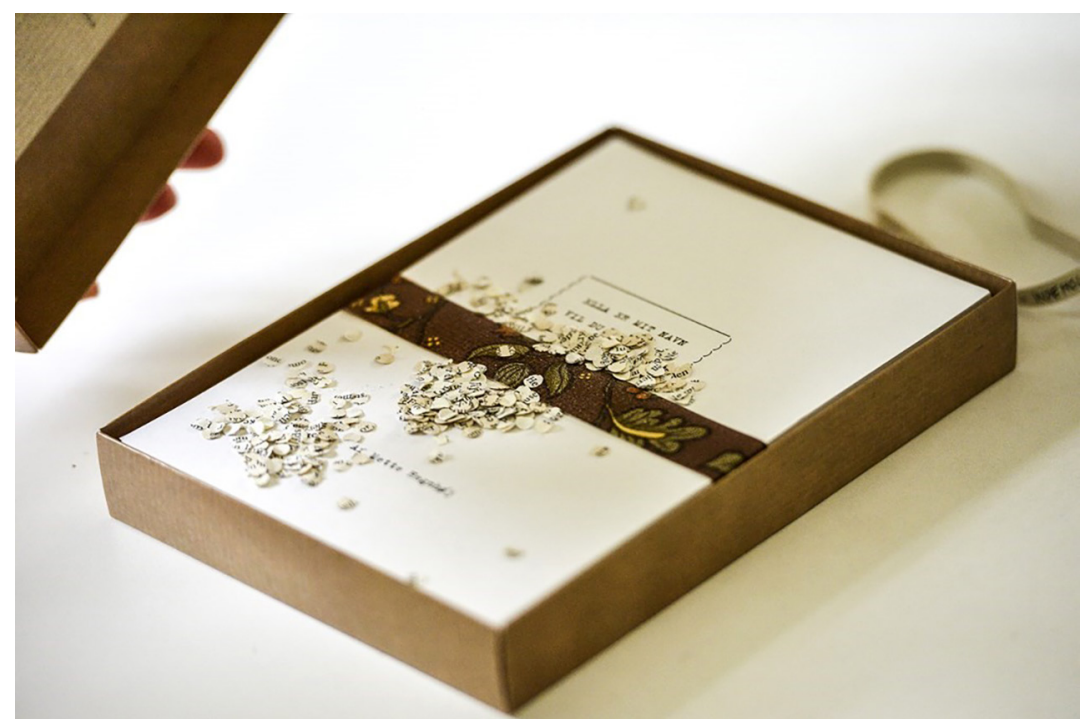

Fig. 1. Ella er mit navn vil du købe det? Af Mette Hegnhøj. Trykt med tilladelse fra Jensen \& Dalgaard.

sælges. Ella beskriver, hvordan hun og moren sælger de gamle bøger i "lykkeposer": "Prøv lykken/ sagde mor/ og mente det ikke" (12).

Der er nemlig ikke megen lykke i baglokalet til antikvariatet, hvor Ella bor sammen med sin mor. Faren er forsvundet. Ella tilbringer sin tid alene blandt bogkasserne. Hun laver små skilte for at hjælpe med salget: "BYENS BEDSTE BRUGTE BØGER", "VI TAGER IKKE BØGERNE RETUR/DE ER BRUGTE NOK I FORVEJEN" og "SOLGT ER SOLGT" (n.p.). Den sidste logik får hun selv at føle, da hun finder ud af, at moren har solgt hendes elskede kat, som hun havde fundet blandt bogkasserne fra et dødsbo. Værket fremstår som Ellas forsøg på at bearbejde tabet af katten - og, indirekte, af faren. Katten og farens fravær kædes sammen. En dag løber Ella ud af butikken, fordi hun tror, hun ser sin far ude på gaden. Da hun vender tilbage, er katten væk. "Solgt er solgt./ Andet havde mor ikke at sige./ Skaffervare, stod der på kvitteringen./ Og kattekilling./ Solgt er solgt, Ella" (119).

Ella reagerer ved at lave nye skilte: "DER ER GRÆNSER FOR, HVAD VI SKAFFER FREMOVER" (n.p.) og ved at gøre oprør mod moren og mod 
den instrumentelle og kommercielle tilgang til bøgerne, som hun forbinder med antikvariatet. Hun gennemhuller alle bøgerne i antikvariatet ved hjælp af en hullemaskine og gør dem derved usælgelige. Historien ender med, at hun forlader antikvariatet. ${ }^{1}$

Ellas oprør mod antikvariatet bliver manifesteret i værkets materielle og visuelle udtryk, der på flere niveauer gør op med den måde at måde at tænke og læse litteratur på, som den trykte bog og traditionelle bogkultur forbindes med. Teksten er sat op, så der sættes fokus på sprogets visuelle dimensioner, med typografiske billeder, f.eks. af den fødselsdagskage, Ella aldrig fik, af det nul, hun føler sig som og af den mistede kat.

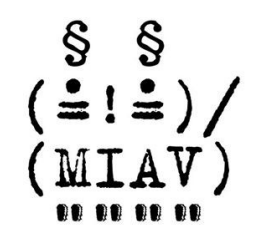

Fig. 2. Typografisk kat. Af Mette Hegnhøj. Trykt med tilladelse fra Jensen \& Dalgaard.

Især kattebillederne bringer associationer til en smileys-æstetik, som vi kender fra f.eks. sms-beskeder og sociale medier, samtidig med at de også skaber allusioner til avantgardens konkretpoesi, f.eks. Apollinaires calligrammes. Værkets brud med den trykte bogs æstetik understreges af dets fysiske format, æsken med de løse ark og poetsneen, der drysser ud mellem siderne under læsning: Der skildres, eller performes, en bevægelse ud af bogen, væk fra antikvariatet og fra den traditionelle litterære kultur, som associeres med dem.

Denne bevægelse understreges, når vi ser nærmere på værket som handelsobjekt. Værkets utraditionelle form med poetsne og løsbladsystem gør det er svært at have med at gøre inden for den litterære kulturs kommercielle og institutionelle rammer. Det er ikke til at finde hos almindelige boghandlere, og det er i skrivende stund udsolgt fra forlaget, fordi det er

1 For en udfoldet analyse af Ella, se Tanderup 2017b. 
276 KULTUR \& KLASSE * $124 * 2017$

HANDEL

besværligt og langsommeligt at producere - hvert eksemplar skal pakkes med poetsne og håndskrevne elatikker. Helt konkret synes værket altså at modsætte sig de logikker, som ellers dominerer bogmarkedet i dag, idet det iscenesætter bogen som et eksklusivt auratisk objekt.

Med sit eksperimenterende format forbinder Ella sig til en neoavantgardistisk tradition for kunstnerbøger, som kom frem i 1960erne. Kunstnerbøgerne var værker, der eksperimenterede med billeder, typografi, bogens format osv. - og som, ligesom Ella, gjorde oprør mod kunstens institutioner, antikvariatet eller museet. Som Thomas Hvid Kromann og Mikkel Bolt påpeger, var 6o'ernes kunstnerbøger udtryk for en modstand mod den igangværende kommercialisering af kunstverdenen. "Kunstnerbogen var et forsøg på at foretage en radikal demokratisering af kunstens produktionsog receptionsforhold," skriver Bolt (113). Ved at cirkulere kunsten i bogform blev det i teorien muligt at undgå den musealisering og kommercialisering af kunsten, som dominerede kunstinstitutionerne. Kunsten skulle ud af museerne og de dyre gallerier og ud til folket, og bogen, som billigt, reproducerbart medium, var midlet hertil. Bolt opsummerer:

Den demokratiserende bestræbelse, forsøget på at udvide kunstens offentlighed eller helt at undslippe den til fordel for en bredere offentlighed, der ikke reproducerer kunstens klassiske klassetilhørsforhold, er kunstnerbogens kritiske potentiale. Med den masseproducerede publikation var det drømmen, at kunstens elitære og eksklusive kredsløb kunne erstattes med en modoffentlighed hinsides galleriets merkantile og museets ophøjede sfærer. (114).

Imidlertid forblev dette projekt ved drømmen, ifølge Bolt. Frem for at føre kunsten ud af gallerierne blev kunstnerbøgerne med tiden selv til genstand for udbredt musealisering og kommercialisering. Et eksempel på denne udvikling er Asger Jorn og Guy Debords Mémoires, der var intenderet som et forsøg på at modstå pengeøkonomien. Oprindeligt blev eksemplarerne af værket således foræret væk - men nu er Mémoires, som Bolt skriver, et "eftertragtet samlerobjekt i en eskalerende Debord-industri" (120). "Debord og bogen er med andre ord blevet det monument, som bogen netop var et opgør med i sin tid" (120).

Denne udvikling gentager sig, når vi vender blikket mod nutidens bogobjekter, f.eks. Ella. Indholdsmæssigt er værket præget af nogle af de sam- 


\title{
277 SARA TANDERUP
}

"BYENS BEDSTE BRUGTE BØGER"

me idéer, vi så i de kunstnerbøgerne; et oprør mod litteraturens traditionelle former og rammer. Men her er der ikke tale om, at kunsten dematerialiseres; snarere om, at litteraturen bliver rematerialiseret - at bogen bliver gjort til en auratisk fysisk ting, der er svær at (re)producere og få fat i. Ella kan således ses som udtryk for en bredere tendens, beskrevet af Marie Kjær Themsen:

\begin{abstract}
Hvor kunstnerbøger i 1960'erne, i en periode, hvor 'kunstnerbøger' opstod som paradigmatisk form, oftet insisterede på bogmediet i en simpel og basal form (billig, masseproduceret, let at distribuere), afspejlende en demokratisk udbredelsesintention, så oplever man i dag ofte en modsat strategi, med et decideret fokus på det materielle og endda på det unikke, eksklusive. En forskel mellem 1960'erne og i dag er selvfølgelig digitaliseringen, som i en vis grad har ophævet behovet for masseudbredelse, hvorfor det materielle i dag bliver noget særligt, noget der keres om. Som en del af en større materialefetish i samtidskunsten ses altså også en decideret passion for papiret, hvor det på én gang simple og klassiske papir er genstand for stadige eksperimenter - der nogle gange antager form af en bog. (123).
\end{abstract}

Som Kjær Themsen påpeger, spiller medieudviklingen en væsentlig rolle for den aktuelle genopdagelse af bogen. Det handler ikke længere om at udbrede kunsten til folket, for bogen er for længst blevet overhalet af elektroniske medier som den billigste og nemmeste reproduktionsform. I stedet handler det om at bevare den trykte bog som en genstand, der har kunstnerisk såvel som kommerciel værdi i sig selv, i en tid, hvor nye medier truer med at gøre den overflødig. Således kan iagttages en tendens til, at man hæver blikket over teksten og - ligesom Benjamins bogsamler - får øje på selve bogen som en værdifuld materiel genstand.

Denne tendens kommer til udtryk i en ny type eksperimenterende værker, som Jessica Pressman beskriver med udtrykket "the aesthetics of bookishness" (2009). Det er værker som Ella, der "udnytter den trykte bogsides potentiale på måder, der gør opmærksom på bogen som multimedium" (465, min oversættelse) - som eksperimenterer med billeder, farver, typografi, papir og format. ${ }^{2}$ Samtidig ses en bredere tendens til, at forfattere

2 Udover Hegnhøjs Ella kan man i denne sammenhæng nævne værker som Jonathan Safran Foers Tree of Codes (2010) og Extremely Loud \& Incredibly Close (2005), Mark Z. Danielewskis House of Leaves (2000), Only Revolutions (2006) og The Familiar (2014.-), Anne Carsons Nox (2009), Salvador Plascencias The People of Paper (2007), Steven Halls The Raw Shark Texts (2007) og danske Oscar K.s Heisenberg-trilogi (2010-12). 
278 KULTUR \& KLASSE * $124 * 2017$

HANDEL

og forlag begynder at fokusere på bogudgivelsers materielle kvaliteter. Forlag som Visual Editions, New Directions eller herhjemme Gladiator satser på at udgive bøger, som er gennemført materielt og visuelt appellerende, gode at røre ved og pæne at have stående i reolen.

Mens kunstnerbøgerne blev til i et oprør mod musealiseringen og kommercialiseringen af kunstverdenen, fremstår denne tilbagevenden til materielt appellerende udgivelser som udtryk for en kommerciel strategi i sig selv; en ny måde at sælge bøger på i en tid, hvor selve teksten ofte kan downloades gratis. Paradoksalt nok betyder den nye opmærksomhed mod bogen som en unik og eksklusiv genstand, at bøger reproduceres mere end nogensinde før. Bogen bliver mere værd, når den spiller på sine auratiske kvaliteter og iscenesættes som en modsætning til de digitale medier - samtidig med at det netop er disse nye medier, som gør det muligt at producere de eksperimenterende bøger til en overkommelig pris. Dette er mit næste analyseeksempel, Abrams og Dorsts' roman $S$, et godt eksempel på: en tilsyneladende slidt gammel biblioteksbog med gulnede sider og håndskrevne kommentarer i marginen - som er blevet en kommerciel succes og kan købes til 355 kr. på Amazon.

\section{S. OG BOGEN SOM SOCIALT MEDIUM}

Når man modtager $S$. fra forhandleren, kommer den i en forseglet sort papkassette. Man skal bryde papirseglet for at komme ind til selve bogen. Ifølge parateksterne på forsiden og titelbladet er der tale om V.M. Strakas roman The Ship of Theseus, der er udgivet på Winged Shoes Press i 1949. Bogen bærer tydelige spor af brug. Den har gulnede sider og er fyldt med biblioteksstempler samt en låneliste bagerst. Mellem siderne er der indlagt fotokopierede dokumenter, avisudklip, fotografier, postkort og breve. Marginerne er fyldt med håndskrevne kommentarer, skrevet med forskellige farver og tilsyneladende af to forskellige personer.

Det hele er selvfølgelig en del af fiktionen. De faktiske forfattere, J.J. Abrams og Doug Dorst, er angivet uden på kassetten sammen med den egentlige titel, S. De gulnede sider, bibliteksstemplerne og de håndskrevne noter i marginerne er alt sammen reproduceret. Ligesom Ella spiller $S$. altså på en forestilling om bogen som en autentisk, gammel ting, samtidig med at 
der faktisk er tale om et nyt masseproduceret værk. Idémanden bag værket filmproducenten J.J. Abrams, siger om værket at:

Det er tænkt som en fejring af det analoge, af den fysiske genstand. I en tid med emails og sms-beskeder, hvor alt flyttes op i 'skyen' på en uhåndgribelig måde, er S. med vilje håndgribelig. Vi ønskede at inkludere ting, man faktisk kan holde i hånden: postkort, fotokopier, sider fra notesblokke, sider fra skolebladet, et kort på en serviet. (Rothman, min oversættelse).

Værket præsenteres i modsætning til digitale medier, som forbindes med det uhåndgribelige, virtuelle og immaterielle. Det er en hyldest til bogen som en ting, som man kan røre ved, og som kan rumme andre ting, spor af brug og andre læsere.

Denne dyrkelse af bogen som en fysisk genstand kan forbindes til en tendens, som Dominik Schrey betegner "analog nostalgi" (2014): en idealisering af det gamle medium i en tid, hvor det ikke længere kan tages for givet. Ifølge Shrey er analog nostalgi "rettet mod støjen, ikke signalet. I bredeste forstand opererer den som en strategi, der genfortryller en genstand gennem æstetisk fremmedgørelse, idet den kendetegnes ved intentionel ufuldkommenhed" (34, min oversættelse). Genstanden, i dette tilfælde bogen, får ny værdi, idet der sættes fokus på 'støjen', sporene af brug og slid. Paradoksalt nok er denne materielle støj, de gulnede sider og håndskriften, i tilfældet $S$., reproduceret gennem digitale teknikker.

Iscenesættelsen af bogen som auratisk analog genstand kan forbindes med en tematisk dyrkelse af bøger og bogkultur i værket. De håndskrevne kommentarer i marginerne tilhører to fiktive læsere, Eric og Jen, som sammen læser bogen The Ship of Theseus og forsøger at finde frem til identiteten på dens mystiske forfatter, Straka. De kommunikerer ved at skrive noter til hinanden i marginen og skiftevis hente og efterlade bogen på biblioteket. De foretrækker at bruge bogen som kommunikationsmiddel, fordi de opfatter nyere medier som usikre og farlige. Eric siger, at han foretrækker at "holde mit liv analogt" $(115)^{3}$ og undgår emails og mobiltelefoner, fordi han tidligere er blevet hacket. Bogen stilles altså igen op i modsætning til de nye medier og fremstilles som et intimt og sikkert rum, hvor de to læ-

3 Alle citater fra S. er oversat af undertegnede. 


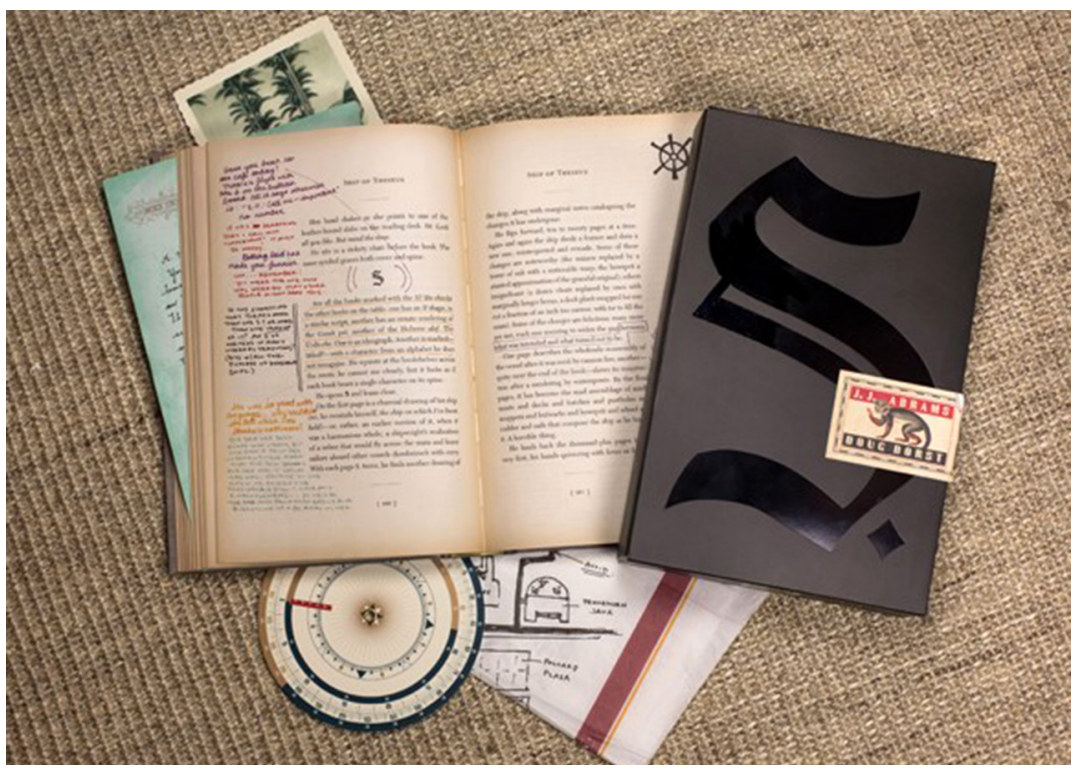

Fig. 3. S. Af J.J. Abrams og Doug Dorst. Trykt med tilladelse fra Mulholland Books.

sere kan udveksle teorier om Straka og hans roman, såvel som personlige erindringer og anekdoter.

Denne forestilling om bogen som et særlig priviligeret, sikkert kommunikationsmiddel kan til dels forklares med den dyrkelse af det gamle medium, som Abrams giver udtryk for. Den trykte bog har altid været reproducérbar, men når den i $S$. stilles over for de nyere medier, bliver den fremhævet som en unik og autentisk ting, der signalerer intimitet og nærvær. Denne fremstilling kan ydermere forklares med, at trykte bøger i værket bliver forbundet med en forestilling om litterær kultur som et rum for modstand mod de nye medier og imod den kommercielle logik, som værket associerer med disse medier. På flere planer i $S$. stilles bogkulturen og det litterære liv således op i modsætning til økonomiske interesser - det gælder, når Jen skal vælge mellem at forsætte med litteraturstudierne og tage imod et markedsføringsjob i New York, eller når Eric lever på vand og brød for at kunne fortsætte sin Straka-forskning. Værket reproducerer 
dermed en klassisk bourdieusk skelnen mellem kunstneriske og kommercielle værdier, hvor den trykte bog og den traditionelle litterære kultur, som forbindes med den, stilles op i modsætning til kommercielle interesser.

Dette modsætningsforhold fremstår tydeligt, når hovedpersonen i den trykte fiktive roman, S., bliver involveret i en politisk konflikt mellem arbejderne på en fabrik og fabrikkens ejer, den magtfulde kapitalist Vevodá. Vevodá, som ifølge Eric og Jen er en fiktivt modstykke til den historiske figur Bouchard, har magt til at kontrollere medierne. Således får han i byens aviser beskyldt en gruppe arbejdere, heriblandt S., for et bombeattentat i byen. Eric og Jen læser karakteren S. som en standin for forfatteren Straka, der selv var politisk aktivist og producerede pamfletter, der modsagde Bouchards version af historien om bombeattentatet (der også, ifølge Eric og Jen, faktisk havde fundet sted). Eric konstaterer:

Pamfletten, [som] VMS skrev, lagde alt det frem, som Bouchard havde forsøgt (+ var lykkedes med) at dække over. Jeg tror at det var dét, som satte gang i alt dette: en krig mellem fortællinger - de fortællinger der er skrevet af de magtfulde + dem, som er skrevet af dem, som udgjorde den største trussel imod deres magt. (272).

Forfatteren og hans værk sættes op i modsætning til den magtfulde kapitalist og de medier, han kontrollerer. Strakas roman bliver læst som et politisk indlæg i en krig mellem kunstneren og kapitalistens versioner af historien. Efterhånden viser det sig, at Straka var en del af en hemmelig forfattergruppe, som modarbejdede Bouchard og bl.a. kommunikerede igennem deres bøger. På flere planer bliver bogen altså associeret med en form for litterær modkultur og iscenesat som et rum for at modstå en kommercielt manipulérbar mediekultur, som associeres med 'hacking', manipulation med og forvrængning af historien.

Denne forestilling om bogkultur og litteratur som idealistisk modkultur til en kapitalistisk mediekultur står imidlertid i kontrast til den måde, værket selv bliver markedsført på. S. er på flere niveauer dybt infiltreret i den nye mediekultur. Som jeg har beskrevet andetsteds ${ }^{4}$, trækker værket på de logikker, som kendetegner en moderne mediekultur - det gælder den måde, det er produceret på, ved hjælp af digitale teknikker, men 
282 KULTUR \& KLASSE * $124 * 2017$

HANDEL

også den måde, Eric og Jens historie er konstrueret på - de lærer hinanden at kende og forelsker sig uden at mødes fysisk førend langt ind i værket. Således føres intim, men anonym samtale i marginerne, som ligner en måde at omgås på, vi kender fra sociale medier. Snarere end at vende tilbage til bogen, som vi kender den, afspejler $S$. således en situation, hvor bogen så at sige bliver "Facebookish" - hvor nye medielogikker påvirker måden, hvorpå vi producerer og bruger den trykte bog.

Denne artikels fokus er på de kommercielle logikker, der omgiver bogen, og derfor vil jeg dvæle ved markedsføringen af værket. Også på dette område er $S$. dybt integreret i en moderne mediekultur, idet værket bl.a. markedsføres via bogtrailers på Youtube og gennem sociale medier - f.eks. via Dorsts og Abrams' produktionsfirma Bad Robots Twitterkonti. Læserne opfordres til at deltage i løsningen af Straka-mysteriet og fordybe sig i en mængde 'ekstra-materiale', som kan findes uden for bogen, bl.a. på en række tilknyttede hjemmesider. Således er det bl.a. muligt på disse hjemmesider at finde alternative versioner af romanens sidste kapitel, ligesom Eric og Jen har deres egne Twitterprofiler, hvor de har fortsat deres diskussion af Straka-mysteriet efter udgivelsen af S.. Værket udvikler sig altså uden for bogen og kan dermed læses som et udtryk for den tendens, medieteoretikeren Henry Jenkins (2006) beskriver som en moderne konvergenskultur, hvor fortællinger i stigende grad udvikles på tværs af forskellige platforme - i det han betegner "transmedial storytelling" - og hvor publikum opfordres til at deltage aktivt i udviklingen af historien på disse platforme.

Jenkins selv beskriver denne tendens meget positivt, som udtryk for en ny demokratisk bevægelse, en deltagelseskultur, hvor publikum inddrages mere direkte i den kulturelle produktion, og medierne anvendes til at udvikle og udbrede kunsten ud over de traditionelle institutionelle rammer - således ikke ulig de visioner, som i sin tid omgav kunstnerbøgerne. "Denne nye mediekultur vækker forventninger om et mere frit flow af ideer og indhold", skriver han således om konvergenskulturen. "Inspireret af disse idealer kæmper forbrugerne for retten til at deltage mere fuldstændigt i deres kultur" (18, min oversættelse). Imidlertid er det værd at bemærke, at deltagelseskultur og mediekonvergens også er effektive kommercielle redskaber. Udviklingen af kulturprodukter over flere platforme medvirker 


\section{SARA TANDERUP}

"BYENS BEDSTE BRUGTE BØGER"

til at udbrede dem, og idet læserne opfordres til at deltage i værkerne, bliver de også inddraget i udbredelsen og markedsføringen af dem. Denne mekanisme er bl.a. beskrevet af Claire Squires og Padmini Ray Murray:

Læsere [...] indkorporeres i den digitale udgivelsesvirksomhed som 'co-promoters'. Lignende co-promotion-modeller ses, idet læsere samarbejder med forfattere, forlæggere og boghandlere omkring promoveringen af bøger på sociale medier ved at dele, re-tweete og re-poste information. (17, min oversættelse).

Konvergenskulturen og de nye medier giver læserne mere at skulle have sagt og mulighed for at deltage mere aktivt i værket. Men den måde, de deltager på, bliver også brugt til at fremme salget af værket. I forbindelse med $S$. kommer denne logik især til udtryk, idet forlaget har udgivet et såkaldt "Reading group kit".

Produktet er målrettet læsegrupper, der således kan købe sig til forskelligt ekstramateriale: et postkort, man kan sende til én af karaktererne i S., et par farvede kuglepenne, så man selv kan skrive noter i marginen, og et par ekstra gåder at løse i relation til værket. Læsernes ønske om at engagere sig i værket i fællesskab med andre læsere; med andre ord, den læserkultur, som direkte tematiseres i værket som værende knyttet til den trykte bog, og som positioneres i modsætning til en kommercielt kontrolleret mediekultur, bliver altså her gjort til genstand for kommercialisering, ja; til en vare i sig selv.

Det er selvfølgelig ikke noget nyt, at bogen er en handelsvare, og at læsning bliver genstand for kommercialisering. Det interessante ved $S$. er, at den fremmaner et billede af bogen som en auratisk fortidsting og som et rum for modstand imod en ny kommercialiseret mediekultur - samtidig med at den fungerer på denne kulturs præmisser med udbredelse over flere platforme og markedsføring på Twitter og Youtube. På den måde afspejler den en bredere tendens, der ifølge Ted Striphas kendetegner den nye mediekultur - en kultur, som nok medfører de muligheder for deltagelse, som Jenkins fremhæver, men som ifølge Striphas samtidig er forbundet med en større grad af kommercielt motiveret kontrol. Han skriver:

Vi bliver lovet en hidtil uset grad af frihed, interaktivitet og brugertilpasning. Hvilket vil sige en større kontrol over den måde, vi bruger vores liv på - og dog siger kritikerne [...] at denne oplevelse af kontrol faktisk er en illusion. Den dækker 


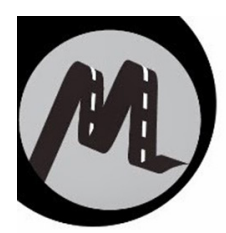

(L) B LittLe, BROWN AND COMPANY MULHOLLAND BOOKS

HOM You never know what's coming around the curve HOME ABOUTUS - BOOKS - EBOOKS AUTHORS ORIGINAL FICTION SWEEPSTAKES NEWSLETTER

Request an S. Reading Group Kit

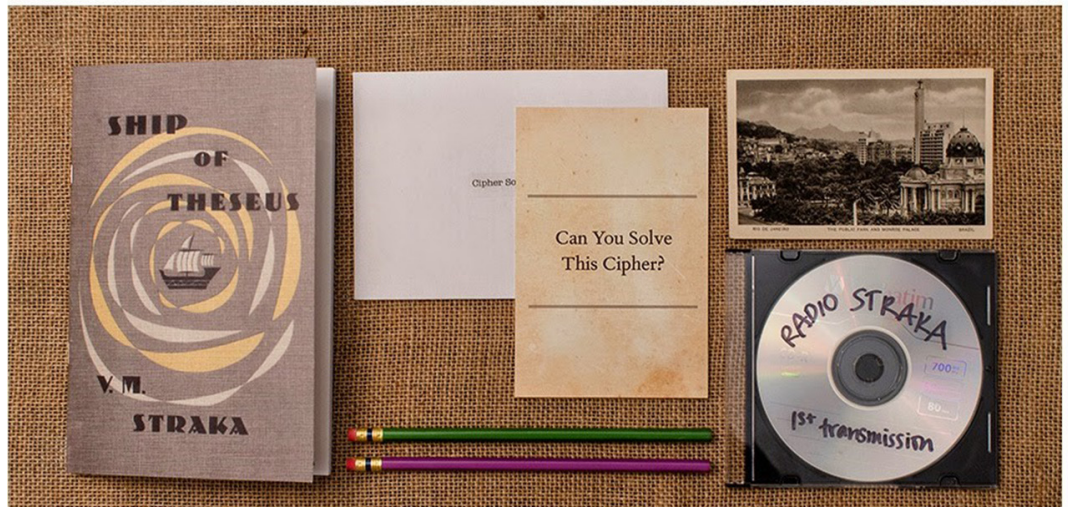

Fig. 4. "S. Reading Group Kit". Trykt med tilladelse fra Mulholland Books.

over, hvordan vi faktisk bliver overvåget, frarøvet data og lokket til at handle på måder, der står i modsætning til vores egne interesser - i højere grad end selv Karl Marx kunne have forestillet sig. I stedet for at være i kontrol [...] bliver vores liv og hverdag i stigende grad kontrolleret af den kapitalistiske akkumulations agenter. (185, min oversættelse).

I S. bliver denne logik ganske vist vendt på hovedet, for her er det det gamle medium, bogen, der lover os frihed til at interagere med andre læsere uden den kontrol, som de nye medier angiveligt medfører. Men tager man værkets kommercielle kontekst med i betragtning, bliver det klart, at den trykte bog i S. netop fungerer som et socialt medium, der inviterer til deltagelse og fællesskab med andre læsere - men hvor deltagelsen samtidig kontrolleres og kommercialiseres, idet værket lægger op til på forhånd bestemte måder at interagere med værket på og sågar sælger os de farvede blyanter til at skrive i marginen med. 
S. kan ses som udtryk for, at de markedsføringsmekanismer og den måde at udbrede fortællinger på, som hidtil har været forbundet med nyere medier, f.eks. computerspil og film, nu også i stigende grad bliver udbredt til den litterære kultur. I en tid, hvor man kan købe bøger i supermarkedet eller på Amazon, sammen med legetøj, sko og makeup, bliver bogen ikke (be)handlet på væsentlig andre betingelser end andre medier eller varer. Den kommercielle kontekst, der omgiver S., vidner om denne situation, samtidig med at værket også afspejler en vis nostalgi, en romantisk forestilling om bogen som en særlig priviligeret kulturel genstand, som stadig hersker i litteraturen selv, såvel som i kulturen generelt.

\section{KONKLUSION}

Ella og $S$. benytter sig begge af materielle eksperimenter for at skabe en illusion om intimitet og autenticitet, om bogen som objet trouvé. Således kan begge ses som udtryk for en situation, hvor vi, ligesom Benjamins bogsamler, får øjnene op for det litterære værks materielle og visuelle, 'auratiske' dimensioner. Der er dog også forskel på de to værker. S. fremstiller bogen som rum for modstand mod en moderne kommercialiseret medieverden. Værket reproducerer en romantisk forestilling om såvel forfatteren som læserne som en art modstandsfolk, der står i opposition til de kapitalistiske tyranner og kommercielle logikker, som angiveligt styrer resten af verden. Bogen bliver her til en sidste bastion for at fordybe sig og forelske sig i litteraturen og i hinanden. Denne logik kommer så til at fremstå en smule hul, fordi værket samtidig deltager på fuld skrue i en moderne mediekultur, hvor fortællinger udvikles på tværs af medier, og hvor folk opmuntres deltage i værket - for at købe mere. Værket selv er et produkt af store mediekonglomerater; det er produceret af Abrams' produktionsfirma Bad Robot og udgivet på store forlag som Canongate og Hachette Books

I Ella er der også et oprør på spil. Her er bogen og antikvariatet dog ikke det, man flygter ind i, men snarere det, man flygter fra. Resultatet er et værk, som i højere grad end S. ligner fortidens kunstnerbøger: hvor det ikke handler om at dyrke bogen, men om at få kunsten ud af butikken, museet eller antikvariatet. Helt konkret udbreder værket sig, når løse sider og poetsne flyver til alle sider, når man læser det. Ikke desto mindre er re- 
286 KULTUR \& KLASSE * $124 * 2017$

HANDEL

sultatet en tilnærmelsesvis unik kunstgenstand. Ligesom kunstnerbøgerne er den blevet til et eksklusivt objekt, praktisk talt umulig at få fat i. I stedet kan man så købe en kodeksversion af værket uden løse sider, poetsne og håndskrevne elastikker til 263,88 kr. på Saxo.com - og således vende tilbage til en mere traditionel måde til tilgå og (be)handle bøger på.

Læst sammen illustrerer $S$. og Ella to forskellige, men beslægtede tendenser i nutidens litterære kultur. Begge sætter fokus på bogen som genstand og vare, samtidig med at de vender sig væk fra den. Ella bevæger sig væk fra bogen som en støvet død ting og peger mod en situation, hvor litteraturen først bliver levende, når den bliver interageret med, gjort til poetsne. Derfor insisterer værket på håndskriften og den besværlige æskeform; på en form, der ikke kan sælges, ikke i stor stil i hvert fald. S. vidner omvendt om en situation, hvor nye medier gør os i stand til at producere og sælge bøger på nye vilkår - hvor det faktisk er muligt at producere bøger med håndskrift og gulnede sider - ikke bare som eksklusive kunstobjekter, men som reproducérbare bøger, der kan købes på Amazon med et par enkelte klik, endog til en rimelig pris. Det er samtidig en situation, hvor bogen bliver ligestillet med andre medier eller platforme for litteratur hvor historien fortsætter efter at bogen er udgivet, og hvor handel med litteratur derfor også bliver udbredt til at omfatte mange andre ting end bøger; f.eks. 'reading group kits' og alskens ekstramateriale.

Begge værker er eksperimenter, som langtfra repræsenterer normen inden for bogproduktion og -handel - endnu. Vi kan stadig købe vores bøger hos fysiske boghandlere, og langt de fleste bøger på hylderne er stadig traditionelle trykte bøger. Ikke desto mindre reflekterer de nye værker et blik på bogen, som fylder mere og mere; blikket, vi allerede så hos Benjamin, på bogen som et samlerobjekt og som en auratisk, eksklusiv genstand - og derfor også med stor sandsynlighed som genstand for mere, ikke mindre, handel i fremtiden.

SARA TANDERUP. Ph.d. i Litteraturhistorie og postdoc ved Center for Litteratur mellem Medier, Aarhus Universitet. Har skrevet afhandlingen "Something to hold on to". Representing Memory and Remembering Literature in Intermedial Literary Works 1978-2014 (2016) samt flere artikler om bogobjekter og eksperimenterende romaner, f.eks. "Nostalgic Experiments", Image \& Narrative 411 (2016) og "A scrapbook of you + me. Intermediality and Bookish Nostalgia in J.J. Abrams and Doug Dorst's S.", Orbis Litterarum 722 (2017). 


\section{"BEST USED BOOKS IN TOWN"}

The Book as a Commodity and Collector's Item in Contemporary Experimental Novels

Literary culture has recently become aware of the book. The spread of new media results in a situation, where the printed book can no longer be taken for granted. The article investigates how the changing cultural and commercial status of the book is reflected in two new experimental novels, Mette Hegnhøj's Ella er mit navn vil du købe det? (2014) and J.J. Abrams and Doug Dorst's S. (2013). Drawing on theoretical perspectives of e.g. Jessica Pressman, Dominik Schrey and Henry Jenkins, I investigate how these works celebrate the book as an auratic object and as a privileged old medium - while also presenting and marketing the book as a commodity, that currently acquires new commercial value exactly because it can no longer be taken for granted. Thus, I argue that the two works in different ways reflect the new ambiguous status of the printed book: it is celebrated as a guarantor of a traditional literary culture and thus positioned in opposition to the contemporary commercialized media culture - while also being (as it always has been) a commodity and thus functioning on the commercial and cultural conditions of this new media culture.

\section{KEYWORDS}

DK: Bogobjekter; kunstnerbøger; materiel kultur; mediekultur; transmedial storytelling

EN: Book objects; art books; material culture; media culture; transmedial storytelling

\section{LITTERATUR}

Abrams, J.J. og Doug Dorst. S. New York: Mulholland Books, 2013.

Benjamin, Walter. "Jeg pakker mit bibliotek ud". Kulturkritiske essays. (Oversat af Peter Madsen og Jørgen Holmgaard.) København: Gyldendal, 1998.

Bolt, Mikkel. "Udfald, kollaps og implosion. Fire bemærkninger om kunstnerbogens politiske potentiale". Danske kunstnerbøger/Danish Artists' Books. Red. Thomas Hvid Kromann: Louise Hold Sidenius: Maria Kjær Themsen og Marianne Vierø. København og Köln: Møller og Verlag Walther König, 2013. 113-122.

Hegnhøj, Mette. Ella er mit navn vil du købe det? København: Jensen \& Dalgaard, 2014. Jenkins, Henry. Convergence Culture. Where Old and New Media Collide. New York and London: New York University press, 2006. 
288 KULTUR \& KLASSE * $124 * 2017$ HANDEL

Kjær Themsen, Marie. "Papirpassioner. Eksempler på kontemporære kunstnerbøger". Danske kunstnerbøger/Danish Artists' Books. Red. Thomas Hvid Kromann: Louise Hold Sidenius: Maria Kjær Themsen og Marianne Vierø. København og Köln: Møller og Verlag Walther König, 2013. 123-132.

Pressman, Jessica. "The Aesthetic of Bookishness in Twenty-First-Century Literature". Bookishness: The New Fate of Reading in the Digital Age. Michigan Quarterly Review 48 (2009): 465-482.

Rothman, Joshua. "The Story of 'S.': Talking with J.J. Abrams and Doug Dorst". New York Times 23. november 2013. 28. oktober 2014. http://www.newyorker.com/books/ page-turner/the-story-of-s-talking-with-j-j-abrams-and-doug-dorst.

Schrey, Dominik. "Analogue Nostalgia and the Aesthetics of Digital Remediation". Media and Nostalgia. Yearning for the Past, Present and Future. Red. Katharina Niemeyer. New York: Palgrave Macmillan, 2014. 27-38.

Squires, Claire og Padmini Ray Murray. "The Digital Publishing Communications Circuit". Book 2.031 (2013): 3-24.

Striphas, Ted. The Late Age of Print. Everyday Book Culture from Consumerism to Control. New York: Columbia University Press, 2011.

Tanderup, Sara. "A scrapbook of you + me". Intermediality and Bookish Nostalgia in J.J. Abrams and Doug Dorst's S." Orbis Litterarum 72.2: 147-178.

Tanderup, Sara. "Bits of Books in Boxes. Remembering the Book in Anne Carson's Nox and Mette Hegnhøj's Ella is my name do you want to buy it." Exploring Texts, Media and Memory. Text, Action, Space 3. Red. Lars Sætre, Patrizia Lombardo og Sara Tanderup (under udgivelse). 